$\begin{array}{ll} & \text { Etnográfica } \\ \text { etnográfica } & \text { Revista do Centro em Rede de Investigação em }\end{array}$

Antropologia

vol. $16(3) \mid 2012$

Vol. $16(3)$

\title{
Trajetórias militantes: do Brasil a Moçambique nas redes da esquerda internacional
}

Militant trajectories: from Brazil to Mozambique through international left-wing networks

Desirée de Lemos Azevedo

\section{CpenEdition}

Journals

Edição electrónica

URL: https://journals.openedition.org/etnografica/2085

DOI: 10.4000/etnografica.2085

ISSN: 2182-2891

Editora

Centro em Rede de Investigação em Antropologia

Edição impressa

Data de publição: 1 outubro 2012

Paginação: 461-486

ISSN: 0873-6561

Refêrencia eletrónica

Desirée de Lemos Azevedo, «Trajetórias militantes: do Brasil a Moçambique nas redes da esquerda internacional», Etnográfica [Online], vol. 16 (3) | 2012, posto online no dia 08 outubro 2012, consultado

o 11 fevereiro 2022. URL: http://journals.openedition.org/etnografica/2085 ; DOI: https://doi.org/

10.4000/etnografica.2085

\section{(c) (i) (8)}

Etnográfica is licensed under a Creative Commons Attribution-NonCommercial 4.0 International License. 


\section{Trajetórias militantes: do Brasil a Moçambique nas redes da esquerda internacional}

\section{Desirée de Lemos Azevedo}

O presente artigo reconstrói as principais redes sociais que levaram brasileiros exilados da ditadura civil-militar (1964-1985) a se tornarem cooperantes na República Popular de Moçambique a partir de 1975. Com base em entrevistas realizadas com alguns deles, pretendo compreender as premissas da relação estabelecida entre os agentes sociais envolvidos nesse processo migratório. As narrativas dos entrevistados atribuem relevância ao contexto histórico de polarização política da Guerra Fria, quando a "esquerda internacional" constituía um campo simbólico e de relações sociais ao qual os entrevistados afirmam terem pertencido. Defendo que este entendimento, estruturado sobre a ideia de militância, forja entre eles uma leitura comum do passado e de suas próprias trajetórias.

PALAVRAS-CHAVE: narrativa, migração, política, Guerra Fria.

Militant trajectories: from Brazil to Mozambique through international left-wing networks - This paper retraces the main social networks that led Brazilian exiles from the civilian-military dictatorship (1964-1985) to became “cooperants" - development volunteers - in the People's Republic of Mozambique after 1975. Based on interviews with some of those exiles, I intend to understand the underlying principles of the relationships established by the social agents involved in this migration process. Their narratives assign major relevance to the historical context of Cold War political polarization, as the "international left wing" was a symbolic and social relations' field to which the respondents claim to have belonged. I argue that this understanding, structured upon the idea of militancy, generates among the exiles a common view of the past and of their own trajectories.

KEYWORDS: narrative, migration, politics, Cold War.

AZEVEDO, Desirée de Lemos (desireelazevedo@gmail.com) - Programa de Pós-Graduação em Antropologia Social da Universidade Estadual de Campinas (PPGA/Unicamp), Brasil. 
EM 25 DE ABRIL DE 1974, UMA INSURREIÇÃO ENTRE OS CAPITÃES DAS Forças Armadas portuguesas marcou definitivamente a história do país, encerrando mais de quarenta anos de ditadura (1932-1974). ${ }^{1}$ As notícias e as imagens registradas naquele dia circulariam muito além das fronteiras portuguesas, sendo recebidas em outras partes com esperança e certo romantismo. Foram publicadas inúmeras fotografias das ruas lisboetas tomadas por passeatas e manifestações artísticas, praças repletas de gentes, entre militares com cravos em suas armas e estudantes em grandes assembleias, imagens que ajudariam a incorporar o 25 de Abril às referências de um paradigma simbólico (Turner 2008 [1974]) que inspirava anseios de transformação social no mundo inteiro.

A Revolução dos Cravos foi imbuída de um forte caráter internacional. Em primeiro lugar, porque o movimento trazia o questionamento à guerra colonial, sangrenta contenda que por mais de uma década consumiu jovens da metrópole e das colônias. As perdas causadas pela guerra foram um golpe final de desestabilização no regime que encontrava opositores em todas as porções - e mesmo fora - do império português. Seu fim daria início também ao processo de negociação das independências. Em segundo lugar, porque a associação do processo com ideais como os de libertação política e igualdade social, principalmente durante seu primeiro período, atrairia o interesse de todos aqueles que então se identificavam como "militantes de esquerda". Portugal seria incorporado entre os itinerários de uma extensa rede social que chamarei de "esquerda internacional" - uma rede capaz de mover pessoas/militantes, bens e ideias por entre fronteiras, colocando em relação, por laços diretos ou potenciais, movimentos políticos europeus do Ocidente e do Leste, asiáticos, de libertação das colônias africanas e também aqueles contra as ditaduras latino-americanas.

Foi através desses contatos que vários militantes da esquerda brasileira, desde 1964 exilados em fluxos contínuos pelas perseguições políticas da ditadura militar (1964-1985), puderam vivenciar a experiência de transformação política em Portugal. $^{2}$ Posteriormente, alguns procurariam também formas de partir para Angola, Guiné-Bissau e Moçambique, obtendo mais sucesso

1 Agradeço os comentários de Bela Feldman, Omar Ribeiro Thomaz e Michael Hall. Os nomes dos entrevistados são fictícios e a transcrição dos trechos de suas entrevistas procura reproduzir a coloquialidade da fala.

2 Os brasileiros se exilaram em muitos países, principalmente na América Latina, até meados dos anos 70, com destaque para o Chile e o Uruguai. À medida que as ditaduras iam proliferando na América Latina, a Europa se tornou um destino mais comum, com destaque para a França. Apesar de fixados no país que lhes concedia asilo, os exilados circulavam muito, mantendo um intenso contato entre as chamadas "colônias" dos diferentes países. Elas encerravam todos os matizes da esquerda brasileira e os colocavam em contato com movimentos políticos de esquerda de várias nacionalidades (também de matizes variados). 
no caso dos dois últimos países, onde conseguiriam se estabelecer em maior número como "cooperantes da revolução".

Considerando que a migração de brasileiros para Moçambique foi um fenômeno restrito numericamente, sobretudo durante os anos de experiência socialista do país, o objetivo deste artigo é traçar as principais vias que tornaram esse trânsito possível, bem como analisar as premissas que sustentaram a relação política estabelecida entre exilados brasileiros e os líderes da independência moçambicana. $\mathrm{O}$ ponto de partida para essa reflexão é um conjunto de entrevistas de história oral realizadas com sujeitos que foram membros do grupo de exilados brasileiros cooperantes em Moçambique. ${ }^{3}$ Ao tomar suas memórias como dados etnográficos estarei refletindo não propriamente sobre fatos do passado, mas sobre sua expressão narrativa no presente. Sendo assim, algumas ponderações parecem necessárias antes de prosseguir.

Considerando as reflexões de Bourdieu (2006 [1986]) e Pollak (1992 [1989]), acredito que a memória seja mais que um arquivo de eventos ou que um produto exclusivo das preocupações do presente. Na análise que segue partirei da perspectiva de que os entrevistados convocam para suas narrativas não apenas eventos selecionados do passado, mas o universo de relações sociais no qual os acontecimentos e personagens se inserem, bem como as categorias, as premissas e as interpretações construídas e compartilhadas no campo social que dão sentido ao narrado.

Suas histórias orais estão em diálogo com as dimensões individual e coletiva das memórias sociais, fazendo parte de amplos processos socialmente negociados de reconstrução de si e de sentimentos de identidade. Entrementes, se essas (re)construções são reinterpretações permanentes do passado, são também

3 Este artigo é uma adaptação do capítulo 3 de minha dissertação de mestrado (Azevedo 201 1), uma etnografia que trata das narrativas, trajetórias e trajetos feitos por exilados brasileiros que se tornaram cooperantes em Moçambique. Ao longo da pesquisa não foi possível estabelecer precisamente a dimensão numérica do grupo (Mayer 2010 [1966]) de brasileiros exilados em Moçambique, embora possa assegurar que ela não tenha sido expressiva em relação ao número de exilados brasileiros ou de cooperantes em Moçambique. Sendo assim, o que está em jogo é a relevância histórica e antropológica dessa experiência. A pesquisa contou com 23 entrevistas individuais sobre as histórias de vida, realizadas em seis cidades brasileiras entre 2008 e 2010 . Foram entrevistados 17 exilados, quatro filhos de exilados e uma cooperante não exilada, além de um ex-ministro moçambicano. Foram realizadas ainda incursões nos seguintes arquivos públicos: Arquivo Edgar Leuenroth, Arquivo Público do Estado de São Paulo, Arquivo Nacional, Arquivo de Memória Operária do Rio de Janeiro. Tive acesso, por fim, a dois acervos particulares: de imagens do fotógrafo Daniel de Andrade Simões e de cartas pessoais de Miguel Arraes (cópias cedidas por Madalena Arraes ao Diário de Pernambuco). A pesquisa partiu de uma lista com cerca de 20 nomes, elaborada por dois dos entrevistados, professores na Universidade Cândido Mendes, no Rio de Janeiro. Ao longo da pesquisa pude multiplicar esses nomes por quatro, com base inclusive, mas não somente, nas indicações dos próprios entrevistados. Hoje, continua existindo uma rede de relações entre os sujeitos da pesquisa, embora mais fluida e com menos pontos de conexão que outrora, já que a maioria se encontra espalhada pelo Brasil (alguns permanecem em Moçambique), não convivendo cotidianamente, embora alguns o façam. 
imprevisíveis e referenciadas simultaneamente nos momentos em que se narra e sobre os quais se narra. Daí que ao longo do tempo alguns de seus elementos se modifiquem e outros se mantenham irredutíveis, remetendo a dimensões solidificadas pela memória coletiva. Não há, portanto, uma separação bruta entre as temporalidades que se sobrepõem no ato de narrar. A forma como a memória se refere e combina referências é fruto não apenas do presente, mas do conjunto do processo social diacrônico em que aqueles que lembram e narram estão inseridos.

De acordo com esse entendimento, defendo que as narrativas dos entrevistados dessa pesquisa guardam em comum mais que acontecimentos abertos à livre interpretação no presente, mais do que temas e categorias coletivamente relevantes; em seus atos de confrontar o passado estão presentes também o que chamarei de premissas comuns, princípios que as narrativas de conjunto mobilizam para elaborar as trajetórias e estabelecer sua coerência e valor. As principais premissas das quais os entrevistados partem para elaborar suas narrativas são as seguintes: os sujeitos da narrativa são constituídos pela ação política (são militantes); sua ação era instruída e motivada pelo conflito entre paradigmas de esquerda e de direita que estabelecia uma oposição categórica e irredutível capaz de relativizar todas as outras; a esquerda é um conjunto de referências simbólicas e campo de relações sociais transnacionais.

O compartilhamento dessas premissas, mesmo pelos sujeitos que hoje não se consideram mais "de esquerda", permite que todos os entrevistados cultivem um corpo de leituras comuns do passado. Minha intenção aqui é perceber como essas leituras são mobilizadas, através de quais categorias e da rejeição de quais outras, para conformar suas narrativas de esquerda. No processo de produção dessas narrativas, os entrevistados procuraram inserir suas trajetórias na dinâmica mais geral dos processos sociais no Brasil e no mundo nos anos 1960 e 1970, quando a política era um campo de dimensões transnacionais em que se estabelecia um conflito entre dois paradigmas simbólicos. ${ }^{4}$ Tendo esta leitura como referência, os entrevistados se situam como atores sociais desse processo histórico, elaborando narrativas sobre suas trajetórias militantes. Nelas, eles se configuram como sujeitos que imaginam em seu passado uma existência coletiva categórica como "militantes".

A esquerda é concebida pelos entrevistados como um conjunto de símbolos e valores capaz de produzir sentimentos de pertencimento social. Por se sobrepor ao mapa das nacionalidades, o paradigma permitiria forjar um campo social transnacional (Glick-Schiller, Basch e Blanc-Szanton 1995), e o pertencimento

4 Os termos campo político e paradigma estão referenciados em Turner (2008 [1974]). Segundo o autor, campos são domínios culturais abstratos em que paradigmas são formulados, são estabelecidos e entram em conflito. Os paradigmas são conjuntos de símbolos e regras gerais que inspiram determinadas ações sociais e excluem outras do universo do ator e que são significados na prática social. Com o termo não me refiro, portanto, a países, regimes, governos ou organizações políticas e suas práticas. 
a esse campo colocaria em conexão organizações políticas e sujeitos sociais de diversas nacionalidades espalhados pelo mundo. Não quero dizer com isso que não havia o reconhecimento de diferenças, tanto quanto de afinidades, no interior do campo da esquerda. As possibilidades de aliança e disputa entre diferentes grupos estavam abertas, sendo múltiplas e móveis; contudo, eram tratadas como internas ao paradigma de esquerda. Há que destacar também que estes modos transnacionais de pertencimento não excluíam aqueles que dependiam de uma perspectiva nacional. Ao ser significado no decurso dos conflitos sociais desenrolados em arenas nacionais, o paradigma era imbuído tanto de perspectivas nacionais quanto de transnacionais, gerando uma sobreposição das categorias e sentimentos de pertencimento coletivo relativo a ambas as dimensões. ${ }^{5}$

\section{UM DESTINO DE MILITANTES}

Exilado em 1970, Sakamoto, então estudante, foi recebido na França por seus antigos "companheiros de militância" do Brasil. No exterior, os brasileiros se organizavam para denunciar as ditaduras latino-americanas. Envolvido com essas ações, Sakamoto se reaproximaria do Partido Comunista Brasileiro (PCB), do qual havia se afastado alguns anos antes de deixar o Brasil. Os militantes do PCB exilados em diferentes países europeus mantinham-se conectados entre si e com aqueles que permaneciam no Brasil. Seus contatos políticos incluíam ainda os demais partidos comunistas (seções nacionais do que fora a III Internacional Comunista), bem como outras organizações "de esquerda", cujos

5 O foco deste texto é a solidariedade internacional no contexto do exílio. Sob este aspecto, a intenção é privilegiar um olhar para as afinidades, razão pela qual não explorarei as diferenças internas à esquerda brasileira. Em primeiro lugar, porque elas perderam importância no momento do exílio, quando o que vemos é a valorização da solidariedade mútua e da articulação de iniciativas entre os remanescentes das organizações da luta armada e os setores identificados como mais moderados, como o PCB e Arraes (contrários à luta armada) ou mesmo Brizola (que se articulou a ela). No Brasil, essas diferenças levaram ao fracionamento das principais organizações políticas, principalmente a partir de 1967. Tentando refletir sobre essa diversidade, Rollemberg (1999) situa suas diferenças em termos de identidade geracional (análise que de certa forma está ligada ao decurso específico do processo histórico no Brasil): uma oposição entre os militantes da luta armada (geração de 68), mais jovens e radicalizados, e a geração de 64, composta por militantes mais velhos, acostumados aos partidos e ao movimento social legalizado. No entanto, é possível dizer que a oposição simbólica entre esquerda e ditadura encontrava condições de relativizar as demais, fazendo com que as diferenças, politicas ou de geração, não invalidassem o reconhecimento mútuo de estarem no mesmo campo político. Como militantes da esquerda, os membros de todas estas organizações desejavam a transformação política e a igualdade social no Brasil e se colocavam na defesa dos interesses do "povo brasileiro". Ainda que mobilizassem diferentes símbolos (como "reforma" ou "revolução") e lhes dessem múltiplos significados, associando-os a distintos símbolos internacionais (como a revolução cubana, a russa ou a chinesa, etc.), todas eram reconhecidas como parte do mesmo paradigma. Chamarei atenção para essa dimensão porque foi ela que prevaleceu nas narrativas dos entrevistados, mesmo ao se referirem ao contexto brasileiro (Azevedo 2011). 
militantes circulavam pelas universidades, sindicatos, grupos humanitários e outros contextos cosmopolitas (Thomaz 2001). Assim como o PCB, os demais partidos da esquerda brasileira também encontravam-se inseridos em redes de contatos cujas dimensões relativizavam a relevância das nacionalidades na conformação de solidariedade política.

Entre os grupos com os quais o PCB pôde estabelecer contatos políticos esteve a Frente de Libertação de Moçambique (Frelimo), organização envolvida em um processo de luta armada pela independência daquela colônia. ${ }^{6}$ Através desses laços, Sakamoto receberia a proposta de juntar-se à Frelimo em seu campo de treinamentos, na Tanzânia. A possibilidade de integrar aquela "luta de libertação nacional" levou-o a deixar Paris em outubro de 1973. Apenas dois anos depois, a partir de 1975, outros brasileiros repetiriam o movimento pioneiro de Sakamoto em fluxos de deslocamento que dariam arranjo ao "grupo dos brasileiros em Moçambique", um grupo social heterogêneo no que se refere à variedade de matizes da esquerda, mas unido por laços de amizade e solidariedade.

Ir para Moçambique durante o período da guerra colonial era uma perspectiva extremamente restrita. Apesar de ampliada após a independência de Moçambique, as oportunidades de deslocar-se para esse país permaneceram sempre relacionadas às redes da esquerda para os exilados brasileiros. Elas se deram tanto através dos contatos estabelecidos entre os próprios indivíduos, quanto daqueles entre as "organizações de esquerda" de várias nacionalidades, duas redes que se conectavam em inúmeros pontos. Esta questão implica em algo que deve ser desde já salientado: os brasileiros que se dirigiram entre 1975 e 1979 para Moçambique não o fizeram na condição de exilados, tampouco receberam asilo político do país. Seu deslocamento ocorreu mediante contratos de trabalho com o Estado, firmados, segundo suas narrativas, por razões políticas. Sakamoto, o primeiro brasileiro a chegar ao país e, portanto, testemunha deste fluxo migratório desde seu início, nos explica:

"[Os brasileiros] foram chegando bastante rapidamente, mas foram chegando aos poucos. Até porque não havia muita condição estrutural assim... p'ra receber gente assim, mas logo depois da independência já tinha brasileiro. E o que chegava era muito por essas indicações políticas, quem 'tava lá e podia dizer: 'não, pode mandar que...' [...] Os que foram chegando era por indicação de partidos, de organizações que indicavam e... ou pediam até

6 Durante a luta pela independência, membros da Frelimo estabeleceram-se fora da colônia, sobretudo na Europa, na Tanzânia e na Argélia (embora o primeiro presidente, Eduardo Mondlane, tenha vivido nos EUA), por onde circulavam realizando contatos políticos. A Frelimo assumiria o poder do país independente em 1975, após a assinatura dos Acordos de Lusaka com Portugal. Em 1977, a frente se converteria em partido marxista-leninista, lançando definitivamente o país em uma experiência socialista. 
p'ra receber gente que 'tava como exilado. [...] Nessa época, por causa das particularidades do... do... do... exílio brasileiro, muita gente já tinha reaproximado com o PCB, em 75, 76, 77 e tal. Principalmente na Europa, havia uma reaproximação de muita gente com o PCB. Mas o próprio $\mathrm{PCB}$ não tinha muita... no exterior, na Europa, por exemplo, não tinha... não levava uma linha muito mais sectária, assim... de dizer que tem que ser ligado ao Partido e tal. Quer dizer, quem procurava... tinha uma abertura no sentido de dizer: 'Dá p'ra ir trabalhar. Pode ir trabalhar lá. A gente pode indicar você' " [entrevista com Sakamoto, realizada em 23 de fevereiro de 2010 em São Paulo].

Dizer que os brasileiros eram recebidos por "indicações políticas" significa que era necessária a confirmação de que o candidato era um "militante", alguém inserido e com relações estabelecidas no interior do campo transnacional da esquerda, cuja trajetória e posicionamento políticos deveriam ser conhecidos entre sujeitos, grupos e/ou redes a ele pertencentes, de modo que este reconhecimento pudesse ser compartilhado.

Sob este aspecto, podemos pensar que muitos acessos ao país poderiam ser abertos levando em conta todos os possíveis avalistas políticos - por assim dizer - existentes no campo de relações da Frelimo. Contudo, é possível afirmar que algumas redes e vias de acesso foram mobilizadas com maior frequência pelos brasileiros que se dirigiram ao país. ${ }^{7}$ Traçarei a seguir as principais redes acessadas pelos entrevistados, as quais eu creio serem representativas do deslocamento mais geral de brasileiros para o país durante o mencionado período. Vale salientar que está sendo exposta apenas uma porção delimitada de uma rede muito mais extensa da esquerda, que então possibilitava deslocamentos transnacionais. ${ }^{8}$ O quadro a seguir foi realizado com base apenas em minhas entrevistas: ${ }^{9}$

7 Segundo o conjunto de documentos a que tive acesso ao longo da pesquisa: entrevistas, livros de memórias e a documentação produzida pelo sistema de informação brasileiro acessadas no Arquivo Nacional e no Arquivo Público do Estado de São Paulo.

8 Em entrevista realizada com o ex-ministro moçambicano José Luís Cabaço, foi mencionada também a importância de Brizola, confirmada por outros entrevistados. Sabemos que o político teve relações com a Frelimo e que pessoas ligadas a ele, como Neiva Moreira e Beatriz Bissio, além do próprio, viajavam a Moçambique. Além disso, a revista Cadernos do Terceiro Mundo, ligada a eles, mantinha um correspondente no país. Entretanto, durante a pesquisa não foi possível encontrar nos documentos ou nos depoimentos informações mais precisas a respeito dessa rede, tampouco pude entrevistar quem foi para Moçambique através dela, ficando esse ponto aberto à investigação.

9 Optei por utilizar famílias, e não indivíduos, como dados da tabela, pois alguns dos sujeitos entrevistados constituem ou constituíam famílias, tendo se deslocado juntos para o país. Os dados incluem apenas três sujeitos que chegaram solteiros ao país - dois casaram com moçambicanos e um terceiro permaneceu solteiro. Os demais são casais heterossexuais, a maioria composta por dois brasileiros. Apenas dois casais eram compostos por um brasileiro e um europeu. Todas as famílias possuem entre 1 e 4 filhos (com exceção do que permaneceu solteiro), uma parte minoritária deles nascidos em Moçambique. 
Quadro 1

Redes sociais que moveram as famílias dos entrevistados para Moçambique

\begin{tabular}{|c|c|c|c|c|}
\hline Redes & $\begin{array}{c}\text { Miguel e Violeta } \\
\text { Arraes }\end{array}$ & PCB & $\begin{array}{c}\text { Esquerda } \\
\text { transnacional }\end{array}$ & $\begin{array}{l}\text { Brasileiros em } \\
\text { Moçambique }\end{array}$ \\
\hline Famílias movidas & 4 & 4 & 4 & 3 \\
\hline
\end{tabular}

Começarei pelo PCB, organização que enviou ao país o único brasileiro a presenciar a substituição da bandeira portuguesa pela moçambicana no dia 25 de junho de 1975. O PCB pôde mover um grande número de brasileiros, exilados ou não, ao longo das décadas de 1970 e 1980. As quatro famílias apontadas na tabela partiram de Moscou (1), do Brasil (1) e da Europa (2), o que nos dá pistas da extensão dos contatos do PCB. A ida de Sakamoto para a Tanzânia durante a luta armada foi um movimento realizado por poucos, já que no início dos anos 1970 a relação entre as duas organizações era ainda tênue, travada por intermédio de militantes de ambas as organizações de passagem ou estabelecidos em Argel. Entre eles, destacam-se Oscar Niemeyer, envolvido em projetos arquitetônicos como o da Universidade de Constantine, e Maurício Seidl, piloto de aviões que trabalhou na Air Algérie, transferindo-se posteriormente para Moçambique.

Com a independência e a necessidade crescente de mão de obra técnica e especializada para o Estado moçambicano, a relação se tornou mais estreita e oficial. ${ }^{10}$ Em 1977, foi articulado um acordo através de Luís Carlos Prestes, então principal dirigente do PCB. A partir daí o partido passaria a "recrutar" brasileiros de forma mais sistemática, ampliando o convite de seus próprios militantes para as redes nas quais estavam inseridos. Através das conexões entre os grupos dispersos do partido, o convite para migrarem para Moçambique com o aval do partido chegou a diversos países, de Moscou, onde estava o próprio Prestes, até os circuitos estabelecidos entre brasileiros espalhados por cidades da Europa Ocidental.

Raquel, entrevistada exilada na Bélgica, soube por Sakamoto da possibilidade de conseguir um emprego em Moçambique. Segundo ela, o brasileiro teria ido à Europa após a independência de Moçambique justamente para "recrutar" possíveis "cooperantes da revolução". Estes contatos chegariam também ao Brasil, onde a estrutura do PCB assumiria a mesma tarefa. ${ }^{11}$

10 Durante o processo de independência e nos primeiros anos seguintes, conformou-se o êxodo de grande número de colonos rumo a Portugal. Uma vez que, em razão da situação colonial, eles compunham parte considerável do corpo técnico e de profissionais qualificados, além dos proprietários de empresas nas áreas de produção e serviços, o país passou a necessitar de quadros administrativos e técnicos para manter o funcionamento da economia e do Estado.

11 Inicialmente levada adiante por Nelson Alves, militar que participou da Guerra Civil espanhola ao lado de renomados militantes do PCB, permanecendo ligado ao partido. 
A segunda rede relevante para o processo se estabeleceu em torno de Miguel Arraes. ${ }^{12}$ Exilado na Argélia, o político teve papel fundamental na mediação de relações entre organizações brasileiras e africanas, especialmente das ex-colônias portuguesas, a partir da Argélia. Seu amplo leque de relações políticas na esquerda brasileira ia de Leonel Brizola ${ }^{13}$ aos grupos de luta armada, passando pelo $\mathrm{PCB}$, apesar das diferenças existentes entre todos estes grupos. Iracema, ex-militante da Vanguarda Popular Revolucionária (VPR) que viveu na Argélia junto a Arraes, declara neste sentido o seguinte:

"Miguel Arraes sempre recebeu todos de uma maneira maravilhosa, podia ser do Partido Comunista... o Prestes mandou muita gente lá p'ra Argel $[\ldots]$ mas ele recebia todo mundo [...] Eu acho que ele nunca confundiu a pessoa, o ser humano com aquilo que ela poderia estar conjunturalmente representando, então passou pela casa dele desde pessoas do PCzão do Prestes, com quem ele tinha boas relações, até os movimentos mais extremados do Brasil. [...] da mesma forma como passou por lá gente da ALN, do MR-8, enfim todos. Da mesma forma que ele recebia todo aquele pessoal que tinha uma ação armada eficaz, a Frelimo, o MPLA de Angola. Quando a Guiné-Bissau conseguiu a sua independência, foi declarado um país independente de Portugal, o governo argelino ofereceu um curso de formação para os quadros do movimento de libertação da Guiné-Bissau que iriam ocupar funções dentro da administração e eles nos pediram para dar aulas" [entrevista com Iracema realizada em 01 de junho de $2010 \mathrm{em}$ Brasília. VPR, MR-8, VAR-Palmares e ALN eram organizações brasileiras adeptas da luta armada].

Em Argel, um agrupamento plural em torno de Arraes articulava iniciativas e atividades políticas com base na solidariedade "de esquerda". Destaca-se uma publicação nomeada $F B I$, que tinha como objetivo promover denúncias contra a ditadura brasileira, divulgar ações, apoiar presos políticos, etc. ${ }^{14}$ O FBI circulava por diversos países europeus, possuindo seções em alguns deles e também no Chile, em torno das quais se articulavam "militantes" de todos

12 Miguel Arraes era governador de Pernambuco no momento do golpe civil-militar. Teve os direitos políticos suspensos pelo Ato Institucional n. ${ }^{\circ} \mathrm{I}$ (AI-1). Foi preso e, solto por um habeas corpus, conseguiu asilo na Argélia, onde viveu até 1979, alcançando grande respeito e prestígio junto a seus anfitriões. De volta ao Brasil, ligou-se ao Partido Socialista Brasileiro (PSB).

13 Membro do Partido Trabalhista Brasileiro (PTB), era cunhado do presidente deposto, João Goulart, e governador do Rio Grande do Sul no momento do Golpe. Foi igualmente cassado pelo AI-1. Tentou frustradamente organizar uma resistência e partiu para o exílio no Uruguai, depois nos EUA. Criou em 1979, em Portugal, o Partido Democrático Trabalhista (PDT), ligado à II Internacional.

14 O FBI era o boletim da Frente Brasileira de Informações. Pode ser consultado no fundo ASMOB do Arquivo da Memória Operária do Rio de Janeiro no IFCS/UFRJ. 
os matizes da esquerda. O boletim também era enviado para organizações pertencentes ao campo da esquerda em outras regiões.

"Tinha um arquivo impressionante e fez um trabalho memorável. Esse boletim serviu de ligação, serviu de... enfim, era uma coisa muito amadora, mas muito importante $[\ldots]$ a gente trabalhava lá religiosamente $[\ldots]$. Olha, eu e E. fazíamos os pacotes, cobríamos praticamente todos os países da Europa Ocidental e da Europa Oriental, cobrimos vários países asiáticos [...] todos os movimentos da Ásia tinha[m] relação com Argel e nós mandávamos os boletins, que saíam em língua francesa [...] As pessoas recebiam em outros lugares, traduziam e redistribuíam, era uma rede realmente muito grande, muito grande... faziam adaptações. Os boletins da Frente Brasileira de Informações no Chile eram totalmente reformulados, mas saía também no Chile, só que com notícias locais" [entrevista com Iracema, realizada em 01 de junho de 2010 em Brasília].

Assim como o próprio boletim circularia por este campo transnacional que a esquerda conformava, pessoas, informações e discussões políticas também transitariam, passando tanto por Argel, quanto por Paris, Santiago e demais comunidades de brasileiros dispersas, fazendo com que as iniciativas políticas perpassassem os circuitos que a esquerda brasileira moldava, sendo discutidas em âmbito transnacional. ${ }^{15}$ Os grupos de brasileiros que na Europa, principalmente em Paris (onde os entrevistados destacaram o papel da irmã de Arraes, Violeta), estavam ligados ao $F B I$ e outras iniciativas que envolviam os militantes na Argélia, fizeram circular as notícias de que os países independentes africanos tinham interesse em receber "militantes", insistindo na necessidade de apoiá-los. Em uma carta recebida por Arraes datada de 24 de maio de 1974, um exilado radicado na Suécia respondia de Berlim à carta anteriormente recebida de Arraes:

"Recebi somente hoje sua carta por causa do atraso na triangulação. Deixei a Suécia por um mês para rever velhos amigos na Alemanha. Estou muito satisfeito com a evolução dos acontecimentos em Portugal e principalmente por causa de suas repercussões na África e, para não deixar de lado nossa

15 Um exemplo dessas iniciativas é o tribunal Bertrand Russel II, em 1973, organizado pelo italiano Lelio Basso, senador do Partido Socialista Independente, cujo objetivo era julgar as infrações aos direitos humanos das ditaduras latino-americanas. Arraes, segundo Rollemberg (1999), fez na primeira sessão do tribunal o ato de acusação ao governo brasileiro. Contudo, em suas cartas podemos ver que ele era inicialmente contrário à realização do evento, mas que se sentia pressionado pelos brasileiros no Chile, entre os quais havia um grande número de militantes da luta armada que se organizavam para retornar ao Brasil - um exemplo de como as discussões sobre o apoio e a participação dos brasileiros não só era coletiva, como circulava pelo Chile (até 1973), Europa, Argélia, etc. 
paixão, no Brasil [...]. O assunto ao qual você se refere é muito interessante. Estaria disposto a discutir minha contribuição pessoal e a de outros companheiros. Será extraordinariamente rico para nós conhecer o processo de construção de um país, com todos os problemas que terão de enfrentar. Aliás, esta disposição já existia antes e muitos companheiros chegaram, em outras épocas, inclusive a discutir o assunto com os próprios companheiros africanos." 16

Ao mesmo tempo, a Revolução dos Cravos levou brasileiros que acompanhavam a situação de Portugal e suas colônias a procurarem informações sobre a possibilidade de se deslocarem para estes países. Com essa disposição, muitos foram à procura de Arraes, por conhecerem seus contatos privilegiados com os movimentos de libertação. Como consequência, principalmente entre os primeiros grupos de "militantes brasileiros" que chegaram a Moçambique, uma grande parte veio por via de contatos estabelecidos pela Argélia, com o aval político de Miguel Arraes. Entre nossos entrevistados, foram quatro famílias. Carla, exilada na França, fez questão de mencionar em seu depoimento que se deslocou para o país no avião que levava uma comitiva de "quadros políticos" para o III Congresso da Frelimo, entre os quais estava Arraes. ${ }^{17}$

Nomeei a terceira via de acesso de esquerda transnacional. Refiro-me a um conjunto amplo e difuso de contatos que um "militante de esquerda" podia estabelecer dentro deste campo transnacional. Portugal tornou-se lugar privilegiado para estes contatos com a Revolução dos Cravos e a subsequente atração de "militantes de esquerda". Os exilados brasileiros que para lá se deslocaram puderam estabelecer ou retomar contatos com os movimentos políticos independentistas de Angola, Guiné e Moçambique, diretamente ou através de organizações da esquerda portuguesa e europeia. O depoimento a seguir demonstra esse conjunto múltiplo de ligações que conformava a esquerda como uma ampla rede social no interior da qual um militante podia estabelecer diversos pontos de contato e traçar outras tantas possibilidades de trajetos.

Wagner, entrevistado cuja última organização de militância fora a ALN, estava exilado na Suécia com outro “companheiro” militante da VAR-Palmares que fez contatos com portugueses desertores da guerra colonial também exilados naquele país. Com a Revolução dos Cravos, o amigo pôde procurá-los em Portugal, onde conheceu militantes da Frelimo:

16 Correspondência de Miguel Arraes pertencente ao acervo pessoal de Madalena Arraes, enviada a Miguel Arraes de Berlim em 26/05/1974. Fonte: Diário de Pernambuco, disponível em: <http://www. diariodepernambuco.com.br/politica/arquivos/cartas.pdf $>$ (acesso 24/02/10).

17 A expressão "quadro político" designa um sujeito destacado nas qualidades políticas consideradas próprias de um militante, geralmente ocupando uma posição de direção em uma organização. A Frelimo chamava-os de "estruturas". 
"Ele simplesmente foi embora para Portugal e lá, com o pessoal do Movimento das Forças Armadas, ele entrou em contato com o pessoal moçambicano. E foi embora para Moçambique. Então ele ficou puxando a gente de lá. Ele disse assim: 'Olha, você tem que mandar alguma carta de algum dirigente de organização brasileira que conheça vocês p'ra provar que vocês são companheiros e mandar um currículo, que aí você vai ser distribuído de acordo com sua experiência profissional. [...] Aí nós, obviamente, pegamos no pé do Apolônio de Carvalho, que era o pai de nós todos [...]. Aí ele deu estas cartas de apresentação p'ra gente, e a gente foi p'ra Moçambique trabalhar lá. Só que aquelas cartas valiam muito, a gente nem sabia que valia tanto assim, chegando lá a gente virou estrutura, dirigente. A Frelimo precisava de quadros, né? Aí enfiou um num Ministério, outro no outro. Aí, foi chegando muitos brasileiros lá" [entrevista com Wagner, realizada em 04 de outubro de 2007 em São Paulo].

De acordo com Wagner, os brasileiros estabelecidos no país passavam a ser também uma via de entrada para outros com quem tinham relações políticas ou de amizade. Eles os convidavam, falavam da experiência no país, encaminhavam seus currículos e serviam como seus avalistas políticos junto à Frelimo. Este importante papel de avalista político era desempenhado tanto por "militantes" conhecidos e respeitados na rede transnacional, como Arraes, Apolônio de Carvalho ou Prestes, por exemplo, quanto pelos membros do "grupo dos brasileiros em Moçambique” com maior prestígio junto à Frelimo.

Por fim, em pequeno número nessa época, estiveram os brasileiros deslocados por meio de entidades internacionais, grupos humanitários ou de cooperação. Moçambique recebeu muita ajuda por seu intermédio, inclusive através do envio de técnicos.

\section{MILITANTES INTERNACIONALISTAS}

\section{VERSUS COOPERANTES INTERNACIONAIS}

"Na década de 80, esse nome cooperante ficou um pouquinho pejorativo. Porque achavam que o cooperante era... tinha regalias, estava ocupando espaço de moçambicanos, mas nesta fase inicial, eu diria que em 1970, o cooperante não... [eles] entram para contribuir, para somar na revolução e na independência" [entrevista com Jairo, realizada em 02 de julho de 2009 no Rio de Janeiro].

"Cooperante internacional" ou, simplesmente, "cooperante" era o termo utilizado pela República Popular de Moçambique para se referir aos estrangeiros que ocupavam os postos, serviços e quadros funcionais deixados vagos pelo êxodo dos ex-colonos. Uma vez à frente do país, a Frelimo procurou realizar 
acordos bilaterais com o objetivo de suprir as carências de recursos, bens e quadros técnicos herdadas do tempo colonial. Assinou acordos de cooperação técnica tanto com países socialistas - entre os quais destaca-se Cuba, URSS, Bulgária, Romênia, China, Coreia do Norte e RDA - quanto com empresas privadas, organizações humanitárias e de voluntariado, internacionais ou de países capitalistas, bem como diretamente com alguns países capitalistas. Estes acordos de modo geral revertiam, para Moçambique, investimentos, aquisição de bens e equipamentos, incorporação de tecnologias, além do envio de pessoal qualificado, geralmente vinculado aos projetos, com a função de administrá-los e a seus recursos. Dado o grau de carência de quadros, o Estado passou também a contratar individualmente técnicos estrangeiros para diversas funções, principalmente nos setores da agricultura, saúde e educação. Os contratados eram, em geral, exilados latino-americanos e militantes de organizações de esquerda com as quais a Frelimo possuísse relações políticas. Todos eram recebidos em virtude dessas relações desenvolvidas pela "militância" no âmbito da esquerda transnacional.

O ex-ministro dos Transportes, José Luís Cabaço, explicou-me as diferentes formas de deslocamento dos estrangeiros que se tornariam "cooperantes" em Moçambique:

"[Nos acordos bilaterais] Eles selecionavam e mandavam estes cooperantes muitas vezes acompanhando um projeto. Às vezes vinham livres, mas muitas vezes vinham acompanhando um projeto de interesse do próprio governo. Então essa era a cooperação das agências, a cooperação estatal [...]. Depois havia o voluntariado, sei lá... nós temos acordos com organizações de solidariedade, com grupos religiosos, associações de vários tipos, sindicatos, não sei quê. A gente pedia e eles arranjavam um processo de mandar gente. Essa era uma outra forma de cooperação, que a gente chamava voluntariado [...]. Alguns até diretamente conosco, eu conhecia... eu conheci gente na Itália, que era das minhas relações, que vinha ter comigo: 'Ah, eu quero trabalhar em Moçambique'. OK, passava o currículo p'ra Moçambique, mandava vir e vinha. Nós que mandávamos vir e tinha diretamente o contrato conosco, mas isso era a minoria [...]. Estes dos refugiados, era uma espécie de cooperação partidária, quer dizer, acordo do partido Frelimo, por meio do governo, com as organizações políticas em que enquadravam os exilados e essas organizações mobilizavam os canais para virem" [entrevista com José Luís Cabaço, realizada em 03 de outubro de 2007 em São Paulo].

Apesar dos diferentes tipos de relações que levavam estrangeiros ao país (comerciais, políticas ou humanitárias) e dos diferentes vínculos que estabeleciam com o Estado (contratados como funcionários públicos - caso dos brasileiros - ou por projetos e agências de cooperação estrangeiros), 
a designação "cooperante" era lançada a todos. Contudo, se a categoria é amplamente declarada pelos entrevistados como sendo aquela pela qual eram classificados, ela pode se mostrar controversa quando o que está em jogo é sua autorrepresentação. No curso de suas narrativas, foi comum os entrevistados mencionarem distinções e limites (inclusive numéricos) que, em sua visão, os forjava como um setor específico entre os "cooperantes":

"nós chamávamos cooperantes individuais, que iam como nós fomos para lá. Individualmente, mas sempre através de uma indicação. Não era... você não postulava p'ra ir: 'Olha só, aqui o meu currículo!' E o cara: 'Ah, é bom! Pode vir!' Tinha que ter uma indicação política. A Frelimo levava lá com um referendo político desta pessoa. E esse foi... os brasileiros que foram para lá, foram com essa... com essa... com esse perfil. Nós chegamos a listar lá uma vez no início... em 79, mais ou menos, mais de 150 famílias brasileiras, né?" [entrevista com Bruno, realizada em 05 de julho de 2007 no Rio de Janeiro]

"Eu me lembro que eu cheguei a contar de elementos revolucionários, não parentes ou o pessoal que eram realmente cooperantes, porque tem essa categoria, cooperante. As pessoas que eram revolucionárias e foram para lá por serem revolucionárias, eu cheguei a contar 108 pessoas, que era um grupo grande, né?" [entrevista com Wagner, realizada em 04 de outubro de 2007 em São Paulo]

Podemos observar que a categoria "cooperante" chega a ser negada em uma postura mais radical, ou relativizada mediante sua adjetivação e especificação. Porém, as duas posturas procuram diferenciações frente à comunidade geral dos "cooperantes", no primeiro testemunho, mas também do conjunto do "grupo dos brasileiros", como parece apontar o segundo. Conforme mencionei anteriormente, a migração iniciada em 1975 com os exilados levou à construção de redes sociais que continuariam sendo mobilizadas para acessar o país até o final da década de 1980, portanto, após a Anistia, quando elas passariam a mover não mais exilados, mas brasileiros interessados em trabalhar no país. Apesar da mudança, muitas vezes eram as mesmas redes que serviam ao novo deslocamento desses brasileiros, fossem estes considerados "militantes" ou não. Entre as redes que passam a proporcionar a ida dos novos "cooperantes não exilados" brasileiros, eu destacaria aquelas conformadas pelo PCB, pelos organismos internacionais e pelas conexões estabelecidas entre os exilados que começam a voltar ao Brasil em 1979 e os que permaneceram em Moçambique, sobretudo através da Abrasso. ${ }^{18} \mathrm{O}$ quadro 2 auxiliará o entendimento do 
processo migratório. Ele ilustra os anos de entrada e saída dos entrevistados em Moçambique.

Acredito que podemos tomar novamente, e pelas mesmas razões, os dados do quadro 2 como representativos de um deslocamento mais geral realizado pelos exilados/cooperantes brasileiros. É possível observar que o ano de 1979 , não por coincidência o da Anistia no Brasil, é o marco para uma mudança no processo de imigração para emigração dos entrevistados. O período entre 1975 e 1977 foi o de maior entrada de brasileiros exilados, vindos principalmente da Europa. Em 1979, após a Anistia, esse deslocamento se altera em direção ao Brasil, em um movimento que se distendeu ao longo da primeira metade da década de 1980.

Quadro 2

Data de entrada e saída das famílias entrevistadas em Moçambique

$\begin{array}{ccccccccccc}\text { Ano } & 1975 & 1976 & 1977 & 1978 & 1979 & 1980 & 1981 & 1982 & 1986 & 1987 \\ \text { Entrada } & 2 & 2 & 9 & 2 & - & - & - & - & - & - \\ \text { Saída } & - & - & - & - & 4 & 4 & 3 & 1 & 2 & 1\end{array}$

É justamente a partir de 1978-79 que começam a chegar os novos "cooperantes brasileiros", vindos em sua maioria do Brasil, mas também da Europa. Eles não eram considerados, nem se consideravam, "exilados", mas até meados dos anos 1980 a maioria se considerava e era considerada "de esquerda", embora alguns não fossem necessariamente militantes. Este perfil irá, entretanto, se alterando ao longo da década até se perder nos anos 1990, quando "cooperantes brasileiros" continuam a ir para Moçambique, já não mais um país socialista, através de redes mobilizadas por empresas multinacionais e ONG.

As narrativas dos entrevistados e as categorias mobilizadas para se definirem e expressarem seus sentidos de pertencimento apontam para a identificação de dois fluxos migratórios distintos, embora coexistentes e partilhando algumas redes, mas que procuram diferenciar conceitualmente. No processo dessa diferenciação, a categoria "cooperante" é por vezes deixada de lado. Devo esclarecer que, em suas narrativas, essa diferenciação não é mencionada como algo que se exprimisse, no cotidiano das relações sociais entre brasileiros, como manifestação de desavenças internas ao "grupo" durante o período em

e envio de muitos cooperantes do Brasil para Moçambique. Seus membros dirigentes eram ex-exilados cooperantes retornados ao Brasil. Posteriormente, estabeleceu também sede em Maputo, onde reunia brasileiros entre militantes da esquerda, do PCB, do PT e sem partido, bem como cooperantes sem histórico de militância anterior. 
que os fluxos conviveram socialmente. Longe disso, eles construíram iniciativas políticas e culturais conjuntas, bem como atividades de lazer, se considerando todos parte do "grupo dos brasileiros" até pelo menos o início dos anos 1980. Uniam-se por laços de amizade e até matrimoniais - como é o caso de um entrevistado - com os "cooperantes não exilados". Será somente a gradual mudança de perfil que afastará os recém-chegados dos veteranos cooperantes/exilados. ${ }^{19}$

É interessante notar que uma distinção semelhante foi observada por Soares (2006) nas narrativas de cooperantes suecos. Segundo a autora, os suecos pareciam identificar duas categorias de cooperantes em Moçambique: os "velhos combatentes" e os "técnicos estrangeiros", que seriam diferentes no que se refere aos sentidos atribuídos à ideia de "cooperação". O "velho combatente" - o termo é emprestado da Frelimo, que assim se referia a seus militantes que participaram da guerra colonial - procura deixar claro que tem na ação política um valor. Ele, em geral, considera ter cooperado "principalmente movido por sua ideologia política. Ainda que alguns não se declarassem oficialmente comunistas, foram quase sempre guiados pela esperança revolucionária da construção de um mundo mais justo e igualitário" (Soares 2006: 160). Compartilhando símbolos da esquerda, nutririam motivações ausentes no discurso dos novos cooperantes, onde o aspecto profissional se sobrepõe, distanciando a ideia de "ajuda humanitária", por exemplo, do antigo ideal do "internacionalismo".

Acredito que, no caso dos brasileiros, questões semelhantes os façam não aceitar sem ressalvas a categoria "cooperante". Considerando a categoria diacronicamente, interpretam como problemáticos os significados que lhe foram atribuídos no contexto moçambicano com o passar do tempo. Afastando-se dos sentidos exclusivamente políticos, escapava ao sistema de oposições categóricas criado pelo conflito entre paradigmas, justamente em relação aos quais os entrevistados compreendem suas trajetórias militantes. Podemos observar a seguir como Wagner, ao falar de sua ida para Moçambique, opõe as categorias "política" e "cooperação". Ele aponta a primeira como aquela pela qual se identifica com a Frelimo, tornando-se igual a seus militantes, enquanto a segunda diria respeito a uma relação de interesse entre desiguais, com a qual não se identifica.

"A SIDA, a agência sueca de desenvolvimento internacional, ela mandava as pessoas, mas nós não queríamos ir pelo esquema da SIDA. [...] Ela inclusive treinava quadros e tal, eles mandavam mais suecos. E estrangeiros

19 Deve ficar claro que os primeiros fluxos de "cooperantes não exilados" compartilhavam muitos dos valores dos exilados, "valores de militante", também considerando "política" a motivação de sua ida para o país. Estas compreensões foram reveladas em conversas informais que pude estabelecer com alguns deles por intermédio dos entrevistados (todos exilados/cooperantes). 
que fossem exilados na Suécia poderiam ir também, mas nós não queríamos ir em um esquema internacional. Nós queríamos ir num esquema político ligado à Frelimo e não a um governo estrangeiro que nos emprestasse à Frelimo. É claro que a Frelimo nos colocou na folha de pagamento dos suecos, depois nós descobrimos isso. O salário que nós recebíamos era pago pelo sueco, era como se nós fossemos suecos; outros que iam da França, eles procuravam cobrar da agência francesa qualquer, não é? Ou seja, de fato nós ficamos naquela odiosa categoria dos cooperantes, a que a gente não queria pertencer, porque o cooperante é o elemento da metrópole com a colônia. É um programa de cooperação que uma metrópole assina com uma colônia. Nós não queríamos isso, mas de fato nós ficamos nisso" [entrevista com Wagner, realizada em 04 de outubro de 2007 em São Paulo].

Declaração muito semelhante apresentou Jacques - entrevistado de nacionalidade francesa, casado com uma exilada e reconhecido como membro do "grupo brasileiro" - quando me explicava as razões que o levaram, após sua formatura na França, a declinar a possibilidade de se inserir no sistema de cooperação internacional de seu país. Em suas palavras, não o interessava: "De jeito nenhum, partir para as ex-colônias francesas, passear lá, com um carimbo na cabeça, de colonizador!” [entrevista com Jacques, realizada em 01 de julho de 2009 no Rio de Janeiro]

As objeções derivadas do entendimento opositivo entre política e cooperação também foram manifestadas por Sakamoto, que trocou a classificação pela de "comissário político", categoria que em sua opinião refletiria melhor a posição que possuía junto à Frelimo desde sua ida para a Tanzânia, onde se tornou professor de português de uma escola para militantes. Após a independência, o brasileiro foi transferido para o interior da província de Maputo, onde continuou com sua "tarefa" de defender e sustentar as posições políticas da Frelimo no processo de formação de seus militantes, assumindo, nesse sentido, um trabalho de "formação política":

“Então, p'ra mim, a figura que eu acho que pode entrar era mais como um comissário político mesmo. Menos do que como um cooperante, né? Eu 'tava lá p'ra tentar sustentar a linha política da Frelimo mais do que propriamente era um cooperante que 'tava colaborando assim e tal. Pelo menos nesse período. [...] Ainda era o mesmo tipo de escola de antes, chamava escola da Frelimo, justamente porque não era escola formal do governo e ainda era então um partido que trazia os alunos lá das zonas libertadas" [entrevista com Sakamoto, realizada em 23 de fevereiro de 2010 em São Paulo].

Nessa escola, que funcionava em regime de internato, o entrevistado não recebia salário, considerando-se também um interno, o que contribui para o 
afastamento da ideia de cooperação. A Frelimo procurava atribuir em seus discursos oficiais um caráter político à cooperação, associando-a a símbolos como o "internacionalismo", tratando-a como uma instituição que fosse ao encontro "da aliança natural entre os países socialistas, o movimento de libertação nacional e social dos povos e a classe operária e forças democráticas dos países capitalistas" (Machel 1983: 152). Entretanto, ao longo dos anos, operando como categoria e símbolo circulante na sociedade, o termo "cooperante" passou a expressar uma posição na estrutura social construída durante o governo da Frelimo, nem sempre possuindo um significado positivo. Acredito que se devam principalmente a essa questão as críticas e resistências de muitos entrevistados em identificar-se com o título.

A passagem dos anos certamente imputou diferenças ao sistema de cooperação, tornando-o cada vez mais formado por "profissionais" em oposição a "militantes". Entretanto, desde seu início, as diferentes redes de cooperação existentes apresentavam distintas situações contratuais e financeiras, gerando novas desconfianças de uns em relação a outros. É interessante notar que não apenas meus interlocutores, mas também os cooperantes suecos entrevistados por Soares (2006), fizeram apontamentos nesse sentido, declarando haver diferenças entre os salários dos cooperantes enviados por distintas agências suecas de cooperação. Como a autora mencionou, a queixa ocorria mesmo quando o entrevistado levava em conta que a carência de bens no país não permitia contrastes acentuados entre as condições de vida.

Nas entrevistas que realizei, essas declarações igualmente surgiram como reprovação de possíveis formas existentes de acumulação financeira de cooperantes à custa de Moçambique. Foi mencionado nesse sentido o fato de "militantes" - de países socialistas e capitalistas - ganharem salários em dólares ou ainda receberem um salário em Moçambique e outro que seria acumulado em seu país de origem. Houve ainda os que elogiaram os cubanos por não representarem gastos, pois sua presença teria sido custeada por seu país. Seria muito difícil no âmbito desta pesquisa confirmar ou descartar a veracidade destas informações, mas considero sua importância na constituição de rumores que correram - e ainda correm - entre os brasileiros, constituindo as bases de uma visão crítica da "cooperação" expressa por alguns entrevistados, que assim negaram a atribuição do rótulo para si e/ou para seu grupo de pertencimento:

"O cooperante ganhava em dólar e o dólar era muito forte. Eles vivam como nababos e nós... alguns se negaram a ter essa vida de nababo, ganhar em dólar. Foram poucos [...] a maioria dos cooperantes viviam melhor do que a maioria da população. Era um privilégio" [entrevista com Ricardo, realizada em 02 de fevereiro de 2010 em Porto Alegre]. 
"Nós fomos p'ra Moçambique como servidores do governo moçambicano, não como cooperantes. Tanto que nós ganhávamos o que ganhava os funcionários moçambicanos, ou seja, muito pouco. Não tivemos a vida de privilégios que depois os cooperantes tiveram. A diferença é radical porque os cooperantes internacionais eram pagos com dinheiro da ONU ou com um dinheiro especial do governo e muito bem pagos [...] tinha supermercado especial p'ra abastecimento de cooperante, então cooperante não passava dificuldades de alimentação, ganham muito bem e em dólar, moram nas melhores casas e são técnicos internacionais considerados cooperantes. Nós não fomos nessa condição. Nós fomos como empregados do governo moçambicano e como tal, nós ganhávamos o que ganhava um moçambicano na mesma função que nós. Então eram salários baixos e não tinha nenhum privilégio. Nós comíamos o que os moçambicanos comiam ou deixavámos de comer o que eles deixavam de comer $[\ldots]$ nem tinha cooperação internacional ainda na época que nós fomos p’ra lá, que depois os cooperantes passaram a ter. Mas, o pessoal que chegou no ano que nós chegamos - E., o N., esse pessoal todo -, ninguém era cooperante, todo mundo tinha a mesma condição que nós. Ou seja... o próprio B., era uma condição.... o próprio P. e a mulher dele [...] era todo mundo empregado do governo moçambicano, não cooperante, cooperante era um ou dois anos depois" [entrevista com Carla, realizada em 01 de fevereiro de 2010 em Porto Alegre].

Conforme os depoimentos apontam, o incômodo mais grave estava nas distinções sociais que a condição de cooperante podia estabelecer em relação à sociedade moçambicana, constituindo uma condição de "privilégio". A maioria dos brasileiros que chegaram ao país em meados da década de 1970 foi contratada pelo Estado para funções compatíveis com sua escolaridade e formação profissional, porém em cargos de importância e responsabilidade provavelmente acima dos que obteriam no Brasil na mesma época, se considerarmos a pouca idade e experiência profissional da maioria. No entanto, puderam galgar, devido à carência de quadros, cargos importantes em ministérios, institutos e empresas estatais, assim como na universidade. Viviam, portanto, uma situação política, social e econômica muito distinta da que possuíam nos países europeus, onde exerciam atividades consideradas aquém de sua qualificação profissional.

Com base no conjunto das entrevistas, acredito que as condições contratuais dos brasileiros que estiveram no país entre 1975 e o início da década de 1980 eram semelhantes. ${ }^{20}$ Contudo, me foi dito diversas vezes que os militantes vinculados ao PCB possuíam condições salariais distintas dos demais brasileiros, em virtude das relações formais entre o partido e a Frelimo. Apesar da dificuldade 
em afirmar se isto acontecia ou se estes comentários são reflexos de suas diferenças políticas, posso assegurar que as condições relatadas pela maioria dos entrevistados se assemelham às presentes no contrato de trabalho de um militante do PCB que me permitiu acesso a este documento de seu acervo pessoal. Assinado em 1982, por ocasião da segunda temporada do entrevistado em Moçambique, o contrato previa: um salário em meticais (moeda nacional), um "quantitativo" de 1.500 dólares, subsídio para aluguel de residência, pagamento das viagens de ida a Moçambique e volta ao final do contrato, passagens de férias uma vez ao ano. Seu contrato possuía uma apresentação padrão como "contrato geral para estrangeiros", com todas as cláusulas fixas, firmado nos termos do decreto-lei 17/75. A exceção é o valor do salário, que assim como os dados pessoais do contratado são os únicos elementos variáveis (preenchidos à máquina). É possível observar ainda a ausência de um campo específico para a designação do valor em dólares, inserido literalmente na entrelinha das alíneas do contrato.

Os termos são compatíveis com os descritos pelo conjunto dos entrevistados, à exceção do valor em dólares, que, segundo os mesmos e de acordo com o que podemos inferir do padrão do contrato, não existia nos primeiros anos. Segundo contaram-me os entrevistados, o polêmico benefício teria surgido inicialmente como uma autorização aos cooperantes para trocarem parte de seu salário naquela moeda, tomando posteriormente a forma desse adicional fixo. Esse processo teria ocorrido a contragosto de alguns brasileiros; entretanto, acabou precedendo uma aceitação coletiva por parte daqueles que permaneceram no país. Segundo conta Rodrigo:

“Cooperante significa que 'tava cooperando com o país. É claro que recebia! Foi engraçado esse processo, porque, nos primeiros anos que nós 'távamos lá, tinha todo um problema com relação às divisas e eles nos pagavam em meticais. A gente só recebia em meticais. Depois tinha gente que queria sair... viajar e não sei quê e precisava de dólar p'ra viajar. Era um transtorno p'ra conseguir aquilo, era complicadíssimo. Começou a haver protesto, não só dos brasileiros... não dos brasileiros, mas da comunidade. Porque havia gente de toda a parte do mundo, que eram considerados cooperantes, que iam p'ra lá com contratos de trabalho com o governo moçambicano, suecos, noruegueses... gente de toda parte... portugueses. Era tudo gente de esquerda... no mínimo humanista que 'tava lá nessa área. Aí o governo resolveu que p'ra evitar esse problema ia pagar uma parte do salário já em dólar. Isso foi em 79. Uma parte do salário em dólar e outra em meticais, a moeda local. E nós éramos cooperantes brasileiros muito radicais, a gente não aceitou receber em dólar! [...] porque ia falir o país aqueles poucos dólares! Depois a gente teve que aceitar, não tinha jeito, até porque a crise começou a ficar muito grande, a crise no país, é... sem comida, sem nada, faltando tudo. E o país abriu uma loja inter franca, que é a loja dos cooperantes, 
que só vendia em dólar, então só os cooperantes... porque você tinha que minimamente... claro que a população passava mal. Nós não, nós tínhamos uma vida bem folgada" [entrevista com Rodrigo, realizada em 31 de maio de 2010 em Brasília].

$\mathrm{Na}$ passagem da década de 1970 para a seguinte, quando se inicia o retorno dos exilados/cooperantes, é também o momento de agravamento da situação econômica de Moçambique. É neste período que surgem os condenados dólares, bem como as "lojas francas", onde se podia comprar produtos inexistentes no mercado comum. O problema do acesso à moeda se colocava na medida em que ela passava a permitir uma condição de vida "bem folgada" e, consequentemente, apartada da situação da população (que não tinha dólares e era proibida de entrar nas lojas francas). Permitia, portanto, ao cooperante, bem como aos diplomatas e às "estruturas" da Frelimo, uma condição material superior à da maioria. A relutância apresentada à mobilização da categoria "cooperante" como forma de autorrepresentação parece nascer principalmente do fato de compreendê-la como contraditória com o papel de "militante" que suas narrativas atribuem a suas trajetórias. Privilégio econômico ou ganho pessoal são, nestas narrativas, como "coisa que não está no seu lugar" (Douglas 1991 [1966]: 50), configurando uma subversão do ordenamento simbólico moldado no paradigma de esquerda. Sendo assim, na medida em que a cooperação se torna incompatível com símbolos como a "revolução", a "igualdade social", ou o “internacionalismo", é gerado seu desconforto em relação à instituição.

O "internacionalismo" é a premissa a partir da qual os entrevistados apreendem suas ações em Moçambique, aceitando a categoria de cooperante na medida em que ela se conforma a esta premissa. A categoria é, entretanto, rejeitada se a cooperação passa a ser concebida socialmente como fonte de "privilégios", quando deveria ser "solidariedade política" a serviço da "construção do poder popular"; se se torna trabalho "burocrático" ou "profissional", quando deveria ser "ímpeto revolucionário" e "disposição militante". A postura do engenheiro soviético, relatada abaixo, pode ser tomada como um caso exemplar do tipo de cooperação que se quer negar:

"Foi durante essa experiência que nos demos conta de quanto a cooperação de técnicos estrangeiros era falaciosa e onerosa. Na província de Nampula, no parque de máquinas, que agrupava as oficinas de tratores e caminhões de uma empresa com cooperação soviética, encontramos completa desorganização. Perguntamos ao engenheiro chefe soviético a razão daquela situação, pois nem o ponto dos funcionários era controlado, e sua resposta foi que ele tinha um contrato de consultor, e não de executante, e esperava as normas que deveriam vir da Secretaria de Trabalho" (Nunes 2000: 274). 
Nesse sentido, as narrativas foram unânimes ao enfatizar a "motivação política" empregada na cooperação. Por repetidas vezes, ao perguntar pelas condições salariais e de vida, obtive como resposta que "nós não fomos para lá por causa disso". Da mesma maneira foi extremamente enfatizada a ideia de que o trabalho realizado era - e deveria ser - encarado como "militância". A leitura comum é a de que estariam colocando lá seus conhecimentos ao serviço da "revolução", por isso trabalhando "10, 12 horas por dia", dedicados à "causa". Suas ações, movidas pelo "engajamento", deveriam se tornar parâmetro não apenas político, mas moral de conduta, válido no julgamento dessas ações, segundo o regime de verdade (Malkki 1995) assumido pela esquerda. Ao longo das entrevistas pareceu-me sempre que a "motivação política" estava sendo entendida como algo que confere não apenas sentido, mas pureza às suas ações, opondo-as àquelas movidas por interesses considerados individuais e, por isso, compreendidas como impuras (Douglas 1991 [1966]).

A condição de vida de um cooperante ou de um funcionário público, fosse ele moçambicano ou estrangeiro, era inegavelmente melhor do que a da maioria da população moçambicana, empobrecida tanto no meio rural como nos "caniços" nas margens urbanas. ${ }^{21}$ Essa situação foi apenas agravada com o passar dos anos e me pareceu ser tomada por muitos entrevistados como capaz de poluir os propósitos de sua presença no país. As narrativas que não se esquivaram a abordar o tema procuravam contrastar essa situação com o engajamento e empenho, próprio e da Frelimo, em acabar com as diferenças e com a necessidade de observação de certo tipo de conduta:

"porque nós não éramos exatamente cooperantes, que cooperante não devia ganhar nada. Eu até discutia isso com um amigo cubano meu [...] e ele mesmo me dizia: 'não, você é cooperante, só que você veio de um país capitalista, quando você voltar p'ra lá... você deve até tentar amealhar algum dinheiro p'ra quando você voltar p'ra lá, porque quando você voltar não vai ganhar nada, pelo contrário talvez até lhe dê uma prisão!' [...] Então eu recebia metade em meticais e metade em dólar, mas o dólar a gente gastava lá mesmo, porque lá tinham aquelas lojas, uma espécie de freeshop que tinha na própria cidade, que era para os cooperantes que ganhavam... que tinha dólar. Isso o povo não tinha acesso, né? Mas não era nada... eles tinham que dar uma possibilidade aos cooperantes, porque tinha cooperantes que não eram bem cooperantes, 'tavam lá p'ra trabalhar e que talvez se não tivessem esses benefícios não ficariam lá. Eu ficaria! Eu não queria... não precisava nada disso, eu... e não só eu, todos os que estavam lá e eram de esquerda! E 'tavam lá p'ra auxiliar... mas nem todos" [entrevista com Igor, realizada em 15 de julho de 2009 no Rio de Janeiro]. 
“[a situação dos cooperantes] era bem melhor, com certeza [...] Tô dizendo assim privilégios... então você ter escola p'ra você, você ter um lugar p'ra comprar p'ra você, que em outros lugares tinha, você ter motorista, ter não sei que... eu não tinha nada disso. [...] agora a diferença era o padrão de vida, morava num apartamento bom de três dormitórios, num bairro que era chamada a cidade de cimento, que era onde os portugueses moravam. Então isso tudo é privilégio em relação ao padrão da maioria, que era zero. [... Não 'tava ficando rico, não era nada do outro mundo [...] ainda assim se quisesse, tinha gente que fazia isso, mas eu não fiz isso, a gente podia ter uma parte do salário em dólar" [entrevista com Felipe, realizada em 09 de abril de 2010 em São Paulo].

Por outro lado, as narrativas também procuravam trazer à tona essas impurezas por meio de rumores constituídos em casos emblemáticos. Geralmente apontam que "tinha brasileiros que...", sentença seguida por uma sorte de possibilidades: "usavam o mercado negro", "faziam negócios ilegais com os indianos", "viviam como nababos", explicitando a existência de um padrão moral de conduta que estava sendo assim infringido, o que é devidamente reprovado. Esboçaram-se também declarações de nunca se ter frequentado ou não ter concordado com - as lojas francas, a "candonga" ou mesmo a troca de salário em dólar, embora alguns tenham acusado a própria participação em uma ou mais destas atividades que, legais ou ilegais, encontram igualmente espaço para a reprovação moral entre as narrativas. ${ }^{22}$

“não, nunca trocamos em dólar, nunca entramos numa loja... sei lá como chamava. [...] E a gente sobrevivia como o resto da população lá, entendeu? [...] A gente acabou tendo um carro lá, que a gente conseguiu comprar, que era importante, a gente tinha uma empregada, que acabava tomando conta das crianças [...]. E tinha uma vida normal lá, tiramos férias uma vez... enfim, uma vida normal, caseira. Ia p'ra praia, como tinha um pouco de recurso, quando tinha camarão, a gente conseguia comprar camarão, porque tinha dinheiro, mas fora isso a gente levava uma vida exatamente como os moçambicanos. Tendo muito privilégio, é claro, morava naquele baita apartamento de frente pro mar, aquelas coisas... [...] Eu nunca senti nenhuma culpa, mas também a gente nunca foi consumista, nunca teve vontades disso ou daquilo, então não fazia diferença, não era por causa disso que a gente 'tava lá, entendeu?" [entrevista com Selma, realizada em 31 de maio de 2010 em Brasília]

A contrapartida dessa situação incômoda é a convocação do compromisso "internacionalista" com a Frelimo e demais "povos em luta” na região. 
O engajamento militante com a "revolução moçambicana" e com a luta "anti-Apartheid" fazem parte da visão que apresentam sobre sua cooperação. Entre as "causas" mais importantes sem dúvida estava a oposição aos regimes racistas da região. ${ }^{23}$ Moçambique, além de aplicar sanções econômicas à Rodésia, serviu de base para os guerrilheiros e oposicionistas da ZANU e do ANC, assim como a Tanzânia havia feito anteriormente em relação à Frelimo. Essa solidariedade fazia parte da relação entre países e movimentos políticos vizinhos da África austral, aproximados pelo paradigma político "de esquerda” e pelos embates com os regimes racistas da região. $\mathrm{O}$ apoio à ZANU foi evocado como parte da "militância internacionalista" por vários entrevistados:

"Eu participei de várias... várias ações ajudando a guerrilha da Rodésia, transportando guerrilheiros, mas foi tudo voluntário. Fui convocado pela Frelimo se eu quisesse fazer ou não, porque eu 'tava correndo risco, né? [...] Eu transportei armamento... tudo p'ra fronteira com a Rodésia. Naquela época que era aquele ditador branco, o Ian Smith e transportei muitos... muitos guerrilheiros [...] Tinha um voo que a gente... ficava próximo dali, ia para um outro país que era a Tanzânia, era Dar-es-Salaam, era a capital da Tanzânia, e a gente... lá era tudo muito rápido e muito organizado. A gente chegava lá com os aviões, com os Boeing, e os guerrilheiros já tavam prontos, entravam e a gente levava. [...] Aí decolava de Dar-es-Salaam direto p'ra Tete. [...] O que aconteceu? Derrubaram o Ian Smith! Eu ajudei a derrubar o Ian Smith!" [entrevista com Igor, realizada em 15 de julho de 2009 no Rio de Janeiro]

"Dei alguns cursos no partido Frelimo. [...] Eu fui instrutor da ZANU, que era a organização lá do Zimbabué, porque eu me dava com dirigentes da ZANU, eles viam que eu falava algum inglês e eles tinham lá um... umas estruturas lá, onde eles treinavam o pessoal deles, aí eles me convidaram e eu trabalhei alguns anos lá dando cursos" [entrevista com Wagner, realizada em 04 de outubro de 2007 em São Paulo].

As demonstrações desse compromisso tiveram ocasiões não apenas nas mencionadas atividades de apoio, mas em situações ritualizadas e simbólicas, como na cerimônia em que o "grupo dos brasileiros" doou ao exército moçambicano rendimentos recolhidos em uma "vaquinha". O reconhecimento mútuo obtido nos marcos dessa identidade e da solidariedade "de esquerda" tornou-se

23 A ONU recomendava sanções econômicas ao regime segregacionista da Rodésia, seguidas por Moçambique. A organização oposicionista ZANU travou até 1980 luta contra o regime, apoiada por Moçambique. Os militantes do ANC da África do Sul encontravam-se também exilados e possuíam bases em Moçambique. 
importante para os brasileiros exilados, selando a relação de cumplicidade e ajuda mútua que os entrevistados consideravam ter com a Frelimo. Talvez seja esta perspectiva que faça suas críticas à cooperação se dirigirem mais constantemente aos cooperantes (aos indivíduos, países e agências) que aos eventuais erros da própria Frelimo.

\section{CONSIDERAÇÕES FINAIS}

A tensão dos conflitos políticos entre direitas e esquerdas durante a Guerra Fria foi muito profunda na África Austral, assim como na América Latina. Para Moçambique, os reflexos foram terríveis. O país viu ser forjada contra si uma guerra de desestabilização a partir de 1977, assumida pela Rodésia do Sul e, posteriormente, pela África do Sul, como represália pelo apoio às organizações de esquerda e às lutas antissegregacionistas no Sul do continente. Naquele contexto de embates irreconciliáveis, múltiplas categorias eram acionadas para dar significação aos conflitos; entre os referenciais raciais, nacionais e regionais, encontravam-se também os de dimensão internacional.

A recusa dos exilados/cooperantes brasileiros em receber salários em dólares e, sobretudo, as narrativas que enfatizam este aspecto de sua passagem por Moçambique, se conformam como posturas "comprometidas" com as lutas assumidas pela "revolução" moçambicana, lutas que eram compreendidas tanto pelos brasileiros, quanto por todo um setor cosmopolita da Frelimo, como parte dos embates internacionais estabelecidos entre direitas e esquerdas.

Essa recusa é exemplo também de como o processo de reconstrução narrativa de suas trajetórias e do contexto histórico vivido revela a existência de uma leitura comum do passado entre os entrevistados, a despeito de hoje, passados tantos anos da volta ao Brasil, possuírem ou não qualquer sentimento de vínculo que possa ser qualificado como identidade. Nessas leituras predominam as temáticas políticas que depositam centralidade sobre a agência nos marcos dos agrupamentos sociais em que tomavam parte. Algo traduzido pela categoria nativa "militância", segundo a qual cada entrevistado vê a si mesmo como um ator político dos eventos narrados, um "militante" em meio a arenas (inter)nacionais de disputas políticas.

Refletindo sobre a incidência dessas trajetórias militantes, foi possível perceber, nas narrativas que enfatizavam a reconstrução de premissas e contextos atribuídos a processos sociais, uma das principais marcas comuns aos testemunhos. Essas premissas são tomadas como capazes de dar sentido a suas ações, decisões e eventos ocorridos no passado. Os entrevistados manifestaram a identificação das ações narradas com um conjunto de símbolos orientadores e marcadores de seu pertencimento social, no passado, à "esquerda internacional", que tomei analiticamente como um paradigma e um campo 
transnacional. A centralidade dada ao conflito, à conformação de opostos políticos e à identidade política a partir do compartilhamento transnacional de símbolos e regras para a ação são prerrogativas de suas narrativas, em que surgem como os sustentáculos de seus deslocamentos internacionais e o substrato de suas relações com a Frelimo.

\section{BIBLIOGRAFIA}

AZEVEDO, Desirée de Lemos, 2011, Os Melhores Anos de Nossas Vidas: Narrativas, Trajetos e Trajetórias de Exilados Brasileiros Que se Tornaram Cooperantes na República Popular de Moçambique. Campinas, Unicamp, dissertação de mestrado em Antropologia Social.

BOURDIEU, Pierre, 2006 [1986], "A ilusão biográfica”, em Marieta de Moraes Ferreira e Janaína Amado (orgs.), Usos \& Abusos da História Oral. Rio de Janeiro, Ed. FGV, 183$-191$.

DOUGlas, Mary, 1991 [1966], Pureza e Perigo: Ensaio sobre as Noções de Poluição e Tabu. Lisboa, Edições 70.

GLICK-SCHILLER, N., L. BASCH, e C. BLANC-SZANTON, 1995, Nations Unbound: Transnational Projects, Post-colonial Predicaments and Deterritorialized Nations-State. Luxemburgo, Gordon and Breach Science Publishers.

MACHEL, Samora Moisés, 1983, A Luta contra o Subdesenvolvimento. Maputo, Partido Frelimo, coleção Textos e Documentos, n. ${ }^{0} 4$.

MALKKI, Liisa H., 1995, Purity and Exile: Violence, Memory and National Cosmology among Hutu Refugees in Tanzania. Chicago, The University of Chicago Press.

MAYER, Adrian C., 2010 [1966], "A importância dos quase-grupos no estudo das sociedades complexas", em Bela Feldman-Bianco, Antropologia das Sociedades Contemporâneas: Métodos. São Paulo, Unesp, 139-170.

NUneS, Célia, 2000, A Armadilha: Incorporação e Exclusão na Sociedade do Trabalho. Rio de Janeiro, Educam/Clacso.

POLLAK, Michael, 1992 [1989], "Memória e identidade social”, Estudos Históricos, 5 (10): 200-215.

ROLlemberG, Denise, 1999, Exílio: Entre Raízes e Radares. Rio de Janeiro, Record.

SOARES, Astréia, 2006, Para Sueco Ver: Uma Reflexão sobre a Cooperação Sueca em Moçambique (1975 a 2004). Rio de Janeiro, UFRJ, Programa de Pós-Graduação em Antropologia e Sociologia, tese de doutorado.

THOMAZ, Omar R., 2001, "Contextos cosmopolitas: missões católicas, burocracia colonial e a formação de Moçambique”, em Peter Fry, Moçambique: Ensaios. Rio de Janeiro, Ed. UFRJ, 135-153.

TURner, Victor, 2008 [1974], Dramas, Campos e Metáforas: Ação Simbólica na Sociedade Humana. Niterói, Ed. UFF. 